\title{
Consuma sem consumir o mundo em que você vive
}

\author{
Hélio Mattar \\ Mattar vislumbrava seguir carreira acadêmica. Formou-se \\ engenheiro politécnico e fez mestrado e pós-doutorado na \\ Universidade de Stanford, nos Estados Unidos, onde ficou por \\ quatro anos. Lecionou na Fundação Getulio Vargas (FGV), \\ depois na Universidade de São Paulo (USP) e no Instituto \\ de Pesquisas Tecnológicas (IPT), pesquisando na área de \\ economia industrial. \\ Em sua carreira empresarial, em parte traçada em paralelo \\ com a acadêmica, foi gerente, diretor, vice-presidente e \\ presidente de dezenas de empresas e organizações nacionais \\ e internacionais, e ainda teve fôlego empreendedor para abrir \\ seu próprio negócio, a rede de restaurantes América. No \\ entanto, em um determinado momento, as coisas mudaram \\ e Mattar passou a trabalhar com questões públicas. Atuou no \\ governo, por dois anos, como Secretário de Política Industrial, \\ Ministro do Desenvolvimento e, ao sair, passou a dedicar-se, \\ exclusivamente, à causa do consumo consciente e em defesa \\ das crianças. \\ Entre 1988-1989, ajudou a fundar o Pensamento Nacional \\ das Bases Empresariais (PNBE) e, em seguida, tornou-se \\ conselheiro da Fundação Abrinq, do Ethos e do Akatu, do \\ qual se tornou presidente.
}

\author{
Revista Gerenciais: O que é o consumo cons- \\ ciente?
}

Hélio Mattar: A humanidade vive um período inédito, em que põe em risco o seu próprio habitat. Repare na água e nas terras agricultáveis: a população consome mais do que o planeta é capaz de renovar. Por meio do consumo consciente, buscase enfrentar essa questão, valendo-se do protagonismo individual. Procuramos fazer com que o consumidor perceba que $\mathrm{o}$ ato do consumo tem impactos sobre o indivíduo, sobre seu bem-estar, as relações sociais, o meio ambiente e a economia. Se as pessoas tiverem consciência do poder transformador de seu ato de consumo, será possível usar o protagonismo individual do consumidor para dar sustentabilidade à humanidade. Muitos falam em sustentabilidade do planeta, mas sempre digo que não tenho essa preocupação, pois é a humanidade que depende da saúde do planeta para sobreviver, para se desenvolver. Apesar de ter consciência disso, o homem, pelo emprego inadequado da tecnologia e pelo excesso de consumo, tem contribuído para que essa situação se agrave ainda mais.

\section{RG: Como surgiu o Instituto Akatu pelo Consumo Consciente?}

HM: Foi fundado em 2001. Por um período de seis meses, funcionou nas instalações do Instituto Ethos de Empresas de Responsabilidade Social e, depois, tornou-se instituto independente. Por que nas dependências do Ethos? Porque fui um dos seus fundadores, e um dos conceitos do Ethos é o de que as empresas somente serão, social e ambientalmente, responsáveis se o consumidor valorizar isso. Se ele não reconhecer a responsabilidade socioambiental como valor e, necessariamente, se essa questão não fizer diferença na hora de escolher o que consumir, então, em algum 
momento, certamente dirão: "ser responsável socialmente não é algo que me traz sustentabilidade de longo prazo no mercado".

A busca da sustentabilidade a longo prazo, obviamente, está presente em todas as empresas, por isso, o Akatu foi formado. Queremos que o consumidor compreenda o que é a responsabilidade social e ambiental; para isso, é preciso que as empresas dêem visibilidade ao que elas estão fazendo e que o consumidor, entendendo seu poder de transformação, atue junto à empresa. Essa foi a origem, mas depois ficou claro que não podíamos ir diretamente à questão. Por quê? A empresa está muito distante do consumidor; por isso, é quase abstrata. $\bigcirc$ que o consumidor vê é o produto e não a empresa. Foi preciso traçar metas; por isso, resolvemos que o ideal seria iniciar a abordagem por questões comuns do dia-a-dia das pessoas, como água, energia e lixo. Começamos por aí, evoluímos para o produto (especialmente alimentos), agregando-lhe o conceito de responsabilidade social e empresarial, e o consumidor percebeu a importância disso, ou seja, a última etapa desse processo - recursos naturais, produtos e serviços, responsabilidade social e empresarial - que tem como objetivo fazer o consumidor perceber o seu poder em relação às políticas públicas, isto é, fazer com que ele pressione os governantes para que dêem condições de o consumo consciente ser praticado. A idéia é pôr as pessoas na discussão sobre a coleta seletiva de lixo e os selos de qualidade para os produtos (como ocorre com os transgênicos). Queremos ativação política, ou seja, que as pessoas tenham voz e se façam ouvir, visando à sustentabilidade por meio do consumo consciente.

RG: Há uma frase famosa entre os defensores do consumo consciente: "comprar somente o que necessito". Você concorda com essa frase? Ela não cria um paradoxo, contrapondo consumo consciente ao capitalismo? Hoje existe o estímulo, cada vez maior, ao consumo, com empresas incentivando a compra do novo e o descarte do velho... É o carro do ano, a roupa da moda. O que você acha disso?

HM: O que se constata, atualmente, é que estamos consumindo mais recursos naturais do que o planeta é capaz de renovar. A produção industrial necessita de recursos naturais, como água, energia e matérias-primas das mais variadas. No entanto, se consumirmos mais do que a terra é capaz de renovar, então, uma hora não haverá o que consumir; por isso, o consumo consciente é a saída para que o capitalismo dê certo. Sem ele, esse sistema econômico, em breve, chegará ao fim, pois a matéria-prima é finita. $E$ há ainda outro agravante: há 1,7 bilhão de pessoas que, hoje, consomem muito mais recursos naturais do que é possível renovar; e outros 4,9 bilhões de pessoas que consomem menos do que precisam para poder viver dignamente. Temos, portanto, uma situação de enorme desequilíbrio. É preciso que as pessoas consumam, para o próprio desenvolvimento dos mercados e, conseqüentemente, do próprio capitalismo. Propomos, assim, a substituição do capitalismo atual, de acumulação, pelo do consumo consciente [sustentável].

Precisamos chegar em um estágio em que o bemestar seja um elemento fundamental do consumo. $\mathrm{Na}$ sociedade atual, consumista ao extremo, o consumo se tornou um exercício de identidade. Tanto é verdade que, verificando o caso das roupas, as marcas são mostradas pelo lado de fora. Há 20 anos não havia essa exposição. Atualmente, a marca representa mais do que a roupa em si e esta não tem, apenas, a função de vestir, mas de ser parâmetro, um instrumento de status entre os consumistas (nós todos). Consumir é o que nos define nos dias de hoje. Mas, se continuar assim, consumiremos o mundo em que vivemos, e uma hora todos esses recursos naturais vão acabar.

O Akatuadota como lema, comoslogan, "consuma sem consumir o mundo em que você vive". Hoje consumimos o mundo em que vivemos, seja do ponto de vista natural ou social. $\bigcirc$ que vemos em termos de violência, de drogas e de terror, em parte, está relacionado com os enormes desequilibrios sociais. Imagine que, em nossa sociedade, bastante pragmática, as pessoas, por meio da televisão e do rádio, sempre vejam e ouçam que os ricos têm infinitas possibilidades de compras, enquanto a maioria das pessoas (não-ricas) não possuem, sequer, o mínimo para sobreviver, para viver dignamente. Isso cria um sentimento ruim na população, um desejo de mudar, de fazer qualquer coisa para conseguir aquilo que deseja. Ouvem-se 
casos de garotos que roubam (e até matam) para conseguir um tênis "de marca". Imagine esse tipo de comportamento ampliado para o panorama mundial. Já o consumo consciente estimula as pessoas a perceberem o impacto do consumo e ensina que ele não deve ser o único objetivo de vida de uma pessoa, mas, sim, um meio para o seu bem-estar. A grande questão é: para a estabilidade, inclusive do próprio capitalismo, o consumo material deve ser compatível com a natureza e com a sociedade.

O que é que se deve pôr no lugar do consumo material que move fundamen-

talmente a sociedade?

É preciso valorizar aquilo que diferencia o homem dos animais - nossas expressões racionais e sentimentais, tão complexas e ricas - por meio de manifestações artísticas e afetivas. Precisamos, portanto, tomar o nosso destino, $\mathrm{e}$ o consumo consciente faz isso, dando ao consumo o lugar de provedor instrumental do bem-estar.

RG: O senhor fala em trocar o capitalismo da acumulação por um que promova o bem-estar, dando mais valor às manifestações da razão, da afetividade e da arte. Contudo, em termos práticos, como o Akatu atua para promover essa mudança de mentalidade? Como desviar o foco do produto e adotar o consumo consciente, valorizando as manifestações que o senhor citou?

HM: A mudança é absolutamente monumental; por isso, ela deve se processar gradualmente. Não é o Akatu que vai fazer isso. Somos um entre infinitos agentes que promovem essa mudança. Além disso, temos aliados como o mal-estar que as pessoas sentem na civilização moderna. Repare que, cada vez mais, cresce o consumo de antidepressivos no mundo - e, mais ainda, nas chamadas "sociedades desenvolvidas". As pessoas não estão se sentindo bem, não estão confortáveis socialmente. Adoto, como exemplo, o fato de as prateleiras das livrarias estarem abarrotadas de livros de auto-ajuda, o que significa que as pessoas estão buscando se ajudar sozinhas, sem o auxílio do outro. Esse comportamento reflete, afinal, o mundo individualista em que vivemos. Na verdade, as pessoas precisam de relações de afeto, para dar sentido às suas vidas. Ao mesmo tempo, não se pode eliminar a agressividade e a competitividade, fatores que impulsionam a sociedade adiante. $O$ que é preciso, nessas situações, é equilibrar esses dois elementos. O Akatu defende esse equilibrio! Numa sociedade em que prevalece o masculino, associado à competição, à agressividade, à razão,

à objetividade, é preciso harmonizar esse pólo com o aspecto feminino, da afetividade, da subjetividade, da intuição e da percepção. Com o equilíbrio, acreditamos, recupera-se o sentido da vida. Esse é, contudo, um grande desafio.

Nós, do Akatu, procuramos mostrar às pessoas 0 poder que $\mathrm{o}$ ato de consumir possui e que, conscientes dessa força, elas podem fazer a diferença, inclusive, individualmente. Se selecionássemos cinco famílias, cada uma com quatro pessoas, ou seja, vinte pessoas, e depositássemos todo o lixo produzido por elas em um apartamento de 100 metros quadrados $\left(\mathrm{m}^{2}\right)$, ao final de suas vidas, obteríamos dez andares lotados de lixo. Falei de cinco famílias! Imagine isso numa cidade de 1 milhão de habitantes. Seriam 50 mil prédios abarrotados. A situação é ainda pior se imaginarmos que, no mundo, existem 1,7 bilhão de consumidores, o que resultaria em 85 milhões de prédios cheios de lixo ao longo de 70 anos..., tudo isso sem contar outros 4,9 bilhões de pessoas não-consumistas, ou seja, cada um de nós é bastante poderoso no seu ato de consumo, por isso deveria usar esse poder para trazer a sustentabilidade ao mundo. As pessoas não consomem em excesso por mal, no entanto, elas precisam entender que esse ato, cumulativo, contribui para a falta de sustentabilidade. Ao tomarem consciência do poder que possuem, essas pessoas começam a compreen- 
der que é preciso consumir com certos limites. Essa conscientização da sociedade é gradual: primeiro, ela reduzirá todo o consumo; segundo, reutilizará tudo até que a vida útil tenha acabado; terceiro, reciclará o que não dá mais para ser utilizado. Ao procedermos dessa forma, estaremos colocando em prática os três Rs - reduzir, reutilizar e reciclar - aos quais o Akatu adiciona um $R$ que dizemos ser "repensar", é preciso repensar o consumo e a vida.

Obviamente que esse processo não se limita aos três Rs. Na medida em que as pessoas reduzem o consumo naturalmente, suas atenções voltam-se para questões mais humanas como as tais expressões da razão, do sentimento e da arte. Imagine todo o esforço e a energia gastos com o consumo e seus problemas, só que focados na produção artística. Vivemos uma época absolutamente extraordinária; nossas crianças acessam, cada vez mais, tecnologia e informações, e precisamos tirar proveito disso. O Akatu, por exemplo, relacionase mais com crianças e adolescentes do que com seus pais, pois os jovens é que farão as mudanças. Os pais precisam ser trabalhados para que não sejam elementos de resistência, cabendo a nós sensibilizá-los para mostrar que suas crianças podem ter um estilo de vida melhor, mais saudável e responsável.

O Akatu sabe que não se muda assim repentinamente. Todo esse trabalho leva, no mínimo, uma geração. $O$ comportamento precisa mudar, e o capitalismo mudará da mesma maneira, conscientemente, transformando os atributos competitivos. Hoje o capitalismo moderno compete, basicamente, no preço, na qualidade, na inovação e no design... Contudo, propomos um capitalismo que, além de competir nesses itens, vai disputar também na responsabilidade socioambiental. De acordo com as pesquisas, o consumidor brasileiro e o internacional vêm mostrando essa carência. Realizamos pesquisas há seis anos e, numa delas, feita com 30 países, verificamos que o consumidor quer que a empresa se torne um agente social, que cuide da sociedade, dos funcionários, do meio ambiente, sendo esse comportamento parte da condição para que uma empresa exista.
RG: Há alguns anos, as pesquisas apontavam que o consumidor brasileiro não fazia distinção entre comprar um produto socialmente responsável ou não. O senhor acredita que tal postura está mudando, ou seja, que estamos mais conscientes do que seja consumir?

HM: Fizemos a primeira pesquisa sobre o estágio da consciência de consumo do brasileiro em 2004. À época, enquanto $43 \%$ da população apresentava um estágio "alto" apenas 6\% estava no nível "mais alto" de consciência. Esse grupo, ainda minoritário, consome conscientemente. Eles privilegiam produtos comunitários e de empresas que tenham atuação social e/ou ambiental. Ainda foram percebidas outras coisas: entre as pessoas de "alta" conscientização, 15\% puniram empresas que não cuidavam das questões socioambientais; entre as pessoas de "mais alta" conscientização, $42 \%$ tomaram a mesma atitude, ou seja, a (re)ação foi quase três vezes maior. Há o outro lado, o das empresas com responsabilidade socioambiental: suas ações foram as que motivaram a escolha de $14 \%$ dos consumidores de "alta e de $28 \%$ dos consumidores de "mais alta" conscientização. Há, portanto, um certo comportamento de militância sobre esse tipo de consumo, e as empresas precisam, afinal, estar preparadas para isso.

Nossas pesquisas ainda revelam outros horizontes, por exemplo, o de que não adianta falar "Olha, compre nossos produtos, porque cuidamos da natureza." Isso é impensável. A empresa, primeiramente, tem de aprender que ter responsabilidade socioambiental é pré-requisito do produto; não é um diferencial. Aliás, o mesmo rumo motivado pelas questões ambientais está sendo tomado pelas sociais. Veja o caso emblemático da Nike, que foi denunciada pelo uso de mão-de-obra infantil. Houve reações de consumidores no mundo inteiro, que deixaram de comprar a marca. Foi preciso, então, que a empresa mudasse a postura. De vilã, passou a promovedora de respeitáveis ações sociais e, atualmente, ela aplica programas de produção, pelo mundo, para garantir o não uso da mão-de-obra infantil; aliás, hoje, ela beneficia a mão-de-obra familiar, que é socialmente formidável e agrada ao consumidor. Foi algo conquistado graças ao poder do consumidor. 
Sobre o que os consumidores vêem como ações socioambientais de valor numa empresa, nossas pesquisas apontam que $40 \%$ apreciam contratações de pessoas portadoras de necessidades especiais (atualmente, 14\% da população brasileira tem contato direto com portadores de deficiência); $35 \%$ valorizam investimentos em educação, em saúde e em organizações não-governamentais (ONGs). É como se elas falassem: "Empresas, dêem as mãos

à sociedade e vamos tentar resolver o que o governo não conseguiu." Isso, entretanto, não significa que os cidadãos (consumidores) não queiram ou não precisem de um governo, mas que eles crêem na necessidade de que haja alguma interferência e que o capitalismo, maior beneficiado pelo consumo, desempenhe papel importante nesse processo.

Adam Smith, há dois séculos, criou o conceito da chamada "mão invisível"', em que nós, sociedade, naturalmente, buscaríamos um equilíbrio ou uma ordem para o sistema movido pelo mercado. Essa conscientização do consumo e consideração dos limites do homem e da natureza são, sim, uma aplicação do capitalismo smithiano. Smith preconizou nosso comportamento há dois séculos.

RG: O senhor falou do papel da criança na mudança de comportamento sobre o consumo. Existe diferença entre crianças, adolescentes, adultos e idosos? Nesse sentido, como o Akatu trabalha para tornar as crianças e os adolescentes consumidores conscientes? Um dos caminhos seria o trabalho em parceria com instituições educacionais e culturais?

HM: Queremos que haja mudança de comportamento do consumidor, mais do que isso, é necessário que ele repense, reduza, reutilize e recicle o seu consumo, contribuindo, com seu próprio ato, para a sustentabilidade. No adulto, a sua forma de consumir está enraizada. Por exemplo, tenho mais de meio século de idade e passei trinta e poucos anos sem ter essas noções, sem saber dos limites de nosso planeta. Eu achava que a natureza era infinita, então, para pessoas assim, fica realmente mais difícil exigir mudanças. Por isso, preferimos enfatizar a relação com as crianças, que não têm vícios, que aprendem fácil e que ficarão mais tempo que nós por aqui. Não significa, porém, que não trabalhemos com adultos. Nós o fazemos, mas por meio de nosso site (www.akatu.net) e da mídia publicitária. $\bigcirc$ objetivo dessa divulgação é sensibilizar os adultos, para que eles, como pais, criem seus filhos fornecendo-lhes os valores do consumo consciente. Já em relação aos jovens, tratamos de outra maneira, pois a importância que eles dão ao consumo está em formação; assim, é possível e mais fácil mostrar que o consumo pode ser usado como ferramenta do bem-estar. Fazemos um grande trabalho em quatro escolas da comunidade de maristas. Iniciamos em Vila Velha (ES) e Natal (AL) e agora estamos em Recife (PE) e Belo Horizonte (MG), com um total de, aproximadamente, 15 mil alunos. Nós chamamos esse trabalho de laboratório, pois, por meio dele, experimentamos as maneiras pelas quais é possível transmitir a idéia de consumo consciente à criança. Além disso, há todo um material e uma metodologia adequados e atuamos na formação docente. Também desenvolvemos publicações para serem trabalhadas em escolas, divididas por ciclos e séries, ou seja, o aluno que lá se formar sairá da escola um consumidor consciente.

Outra ação merece destaque. Fizemos uma parceria com a Rede Globo para introduzir o tema "consumo consciente" como merchandising social nas novelas, para que os personagens começas- 
sem a agir como consumidores conscientes e, por meio de suas ações e falas, esclaressem o telespectador, sobre o que é isso e qual a importância desse assunto. Esses personagens fictícios, de certa forma, são modelos para a sociedade.

\section{RG: Em relação ao consumo consciente no} mundo, as populações possuem suas diferenças? Existem mais desses consumidores em países desenvolvidos? E, focando apenas o mercado brasileiro, qual a proporção da representatividade entre as classes socioeconômicas?

HM: Existem grandes diferenças entre o consumidor brasileiro e o de diversos países ricos, especialmente, se compararmos as populações da Austrália, dos Estados Unidos, da Alemanha e da Inglaterra, mais exigentes, e as que mais cobram ações responsáveis das empresas e dos governos. Nos países desenvolvidos, esses consumidores representam de $50 \%$ a $60 \%$ da população, o que é bom - lembrando que o Brasil tem apenas $6 \%$ com consciência "mais alta". Além disso, lembro da mídia que, em países desenvolvidos, está sempre pautando o tema. Nos Estados Unidos, por exemplo, ela atua desde 1960, enquanto, no Brasil, a questão começou a surgir na segunda metade da década de 1970. Ressalto a mídia, pois, acredito que ela, realmente, desempenha um papel de formação, de educação e de sensibilização social.

Agora, sobre a distribuição de consumidores conscientes entre as classes socioeconômicas, fiquei surpreendido com os dados de nossa pesquisa. Assim como a grande maioria das pessoas, acreditava piamente que os conscientizados estavam entre os mais abastados e os mais ricos. No entanto, veja que bom: existe, na verdade, uma homogeneidade. Dos 6\% dos brasileiros com "mais alta" consciência, 52\% são das classes C e D, e $48 \%$, das A e B.

RG: Então, a conscientização é homogênea, mas o que dizer de como as pessoas vêem o consumo consciente? Ele é igualmente percebido pelas diversas classes socioeconômicas?

HM: De fato, os níveis de percepção são diferenciados, e muito disso se deve ao meio social. Essas percepções do consumo consciente podem vir por meio da escola, dos amigos, do trabalho e dos personagens da televisão. Especialmente nas classes $\mathrm{C}$ e $\mathrm{D}$, as pessoas tendem a absorver os conceitos por meio das práticas do dia-a-dia. Para eles, valem exemplos como "você sabia que, se 1 milhão de pessoas, durante um mês, fecharem a torneira na hora de escovar os dentes, a água economizada será equivalente a 12 minutos do que cai pela catarata do Iguaçu? Imagine o quanto de água dará para economizar lavando a louça, a roupa, o carro, o chão". Acreditamos que são essas mensagens que fazem o consumidor mudar. No entanto, temos visto que a pesquisa qualitativa, aprofundada e antropológica, como tem sido desenvolvida, poderá nos dar indicações firmes sobre como promover a mudança de comportamento do consumidor.

\section{RG: Como o Akatu avalia o que as empresas} fazem e o que elas afirmam fazer?

HM: Nós dizemos que as organizações trabalhavam o paradigma do produto e o da imagem: pelo primeiro, a empresa é o produto, ou seja, aos olhos do consumidor não havia qualquer empresa; pelo segundo, a empresa é a imagem, ou seja, ela precisa e tenta atrelar sua imagem à de seus produtos, visando transmitir valores, tais como aventura, qualidade, status. $\bigcirc$ que acontece é que essa imagem advém não só das publicidades, mas das relações que a empresa mantém com a mídia, com seus funcionários, com a comunidade e, cada vez mais, com as questões socioambientais.

$\bigcirc$ primeiro passo a ser dado no paradigma da imagem é o da adequação dos produtos às necessidades do consumidor. Inicialmente, o produto existia, mas, com o passar do tempo e com a crescente conscientização das pessoas, elas perceberam seu poder de barganha e passaram a exigir produtos sem qualquer sinal de defeito, com melhor qualidade, sabores, tamanhos, embalagens e outras variáveis. Já o segundo passo está associado à relação existente entre a empresa e tudo o que existe à sua volta, ou seja, os seus colaboradores, a comunidade e o meio ambiente. As pessoas estão atentas às empresas, por isso julgam suas ações e, também, suas nãoações. Por causa disso, devido à pressão exercida pelas pessoas, as empresas se vêem obrigadas a trabalhar não somente o produto, mas também 
suas relações. No entanto, isso implica algumas complicações à organização. Explico: quando o foco é o produto, fala-se em perfeição, em coisas técnicas e teoricamente mais fáceis de serem resolvidas; quando o foco são as relações humanas, passa-se a lidar com a imperfeição - pois um produto pode ser perfeito, mas uma relação, não. Ou seja, nessa situação, você trabalha com a expectativa do outro. Isso significa dizer que pode acontecer de a empresa fazer "tudo certinho" numa relação com seu funcionário, mas ele se mostrar insatisfeito. Por quê? Porque ele pode ter criado uma expectativa fantasiosa, como a de querer ser o presidente da empresa, ou a de ter uma promoção ou um prêmio. Há expectativas que não têm base na realidade e há aquelas, com base na realidade, que a empresa não percebe. Também é ruim.

Atualmente, não basta à empresa dedicar-se somente à produção, é preciso que ela zele também pelas suas relações, porque é, por meio delas (e de experiências, de melhorias e da maturidade), que o consumidor formará a imagem ou saberá "quem" é a empresa. A imagem projetada "para fora", para o consumidor, é a proveniente desse processo. A verdade será aquilo que, efetivamente, calar fundo no coração dos consumidores. O que é interessante é que nada disso é estável. Assim, mesmo que não erre, a empresa poderá sofrer danos, ou, o contrário, mesmo que erre, ela poderá sair ilesa. Vou explicar tudo isso: quando uma empresa tem bons relacionamentos (com seus colaboradores, parceiros, comunidade etc.), mesmo quando ela erra, os consumidores podem não enxergar isso, pois ela blindou-se emocionalmente! Já quando uma empresa faz tudo perfeitamente, mas não tem boas relações, isso a prejudica, porque as pessoas insatisfeitas falarão mal dela, e será essa a imagem fixada pelo público, ou seja, cada vez mais, as empresas serão (ou as percepções sobre elas serão) aquilo que dizem dela e não o que ela diz de si própria. Isso representa uma enorme mudança de paradigma.

As empresas que têm o marketing social como algo importante, comum e natural, certamente terão menos problemas com sua imagem - elas refletem o que, de fato, são. Já as outras, que tentam fazer "uma ação bonitinha" para dar sustentabilidade à marca, vão gastar milhões em ações e, na primeira titubeada, serão desmascaradas. Essas organizações perceberão que o mercado funciona como um enorme bumerangue e que o marketing social inconsistente, não coerente com a ética, é perceptível.

O Akatu não avalia as organizações e empresas, mas indica quais caminhos podem seguir para fazer um bom, consistente e ético marketing social. É importante dizer também que o Akatu não apóia marcas, ele recebe apoio de algumas empresas - atualmente, são 65 empresas que, em maior ou menor grau, nos apóiam. Temos gente que, inclusive, ajudou nosso trabalho antes mesmo de ele ser "inaugurado", como é o caso do do Banco Real, da Nestlé, da HP, do Banco Boston. Temos algumas empresas estratégicas, tais como a Fundação Itaú Social, - WalMart, o Pão de Açúcar, os Maristas, que nos fornecem recursos em grande quantidade. O fato de o Akatu ser uma ONG apoiada por essas empresas significa que elas vêem no consumidor consciente algo que pode ser importante para a construção da própria marca e, portanto, o Akatu pode ser um potencial aliado.

Esperamos que, com o passar do tempo, mais e mais empresas ${ }^{2}$ e mais e mais pessoas venham apoiar o Akatu. Gostaríamos de que também os alunos universitários nos olhassem mais aten- 
ciosamente, pois lutamos por uma causa que se concretizará a longo prazo, sendo, por enquanto, abstrata e difícil de ser percebida. $\bigcirc$ nosso objetivo é mudar o comportamento na sociedade como um todo, para dar sustentabilidade ao planeta.

RG: Você acha que os cursos tradicionais de graduação, das áreas relacionadas ao consumo, estão tratando do consumo consciente?

HM: $\bigcirc$ fato de eu, de outros membros do Akatu e de organizações afins à conscientização participarmos de entrevistas e palestras em universidades mostra que elas estão começando a nos ver. No entanto, o consumo consciente não faz parte do currículo oficial. Nós o inserimos nas escolas dos Maristas, e pretendemos estendê-lo ao ensino público. Na Universidade Estadual de Campinas (Unicamp), veteranos aplicam um trote que, em vez dos eventos tradicionais (pichação, festas, brincadeiras etc.), vislumbra passar aos novatos as bases do consumo consciente. É ainda algo extracurricular, mas queremos o consumo consciente nas matérias dos currículos escolares e universitários, nas aulas de geografia, história, química, física, biologia etc. Atualmente, concentramos esforços na elaboração de materiais para adoção nos ensinos fundamental e médio, e, futuramente, para os universitários, lançaremos um programa que premia os melhores Trabalhos de Conclusão de Curso (TCCs) de consumo consciente.

RG: Como se dividem as atuações do Akatu, junto ao governo, às empresas e aos cidadãos?

HM: Junto ao governo, o que se faz é lobby, mas é preciso também o apoio de empresas e da organização dos cidadãos. Para o público geral, nossa ferramenta de comunicação é somente o site, pois quaisquer outros meios seriam dispendiosos demais. Embora atuemos com instituições de ensino, visando à conscientização de crianças e jovens, nosso forte é a atuação em parceria com as organizações, a qual possibilita a nossa ida até uma empresa, uma organização, uma associação, para formamos líderes que, por sua vez, falarão diretamente à comunidade. Não trabalhamos com o consumidor, mas com o líder capacitado, sensibilizado, mobilizado, que leva o tema adiante.
Nas escolas é parecido; falamos com professores, coordenadores, diretores para que eles tornem-se divulgadores. É claro que também conversamos com os alunos, com as crianças. Quando tratamos com empresas, procuramos as que chamamos de disseminadoras, que têm força (capital, estrutura etc.), porque possuem um público enorme, entre consumidores e colaboradores. É o caso da Coca-Cola, que divulgou nossos cartazes em 100 mil pontos-de-venda, e da Rede Globo, que divulgou um filme publicitário nosso - acreditamos que chegou a mais de 100 milhões de pessoas.

$R G$ : Vocês focam a relação com o consumidor, mas como seria esse trabalho para o produto? Porque, para se ter um consumo consciente, é preciso ter produtos adequados. Há algo nesse aspecto?

HM: De fato, para existir a prática do consumo consciente, é preciso que haja o que consumir. É necessário haver produtos adequados e informações sobre a relação da empresa com o social e com o ambiental. No aspecto da informação, desenvolvemos um trabalho extenso, pioneiro no mundo, chamado "Escala Akatu de Responsabilidade Social e Empresarial". Pesquisamos 630 empresas do país e selecionamos 60 práticas presentes nas empresas mais responsáveis nos aspectos social e ambiental. Então, perguntamos para $43 \%$ da população brasileira quais as práticas que achavam ser importantes. Tabulamos tudo e demos pesos a essas práticas, o que resultou na criação de uma escala que informa ao consumidor o estágio de responsabilidade social e ambiental da empresa.

Agora, falando em produtos, não é nosso objetivo adequá-los, pois essa é função das empresas, mas informamos o consumidor sobre produtos que tenham o apelo à conscientização, como aqueles que trabalham com refil, que consomem pouca energia, que são recicláveis etc. Pelo site, pode-se ainda consultar informações sobre vários selos de qualidade, da área de alimentos a de produtos gerais. Procuramos nos concentrar em desenvolver a consciência do consumidor, até porque, acreditamos que eles, naturalmente, exigirão que as empresas desenvolvam produtos mais adequados. 
Gostaria de enfatizar, ainda, que o governo, suas instituições e afins desempenham papel essencial em relação a esse tema. Veja a Companhia de Saneamento Básico do Estado de São Paulo (Sabesp). Estimamos que ela perde, aproximadamente, de 40 a $45 \%$ da água que produz na tubulação até chegar na casa dos consumidores. Ou seja, por mais que façamos um esforço grande com o consumidor, temos ainda um literal vazamento de água nas tubulações da Sabesp. Pense o que se perde em recursos, em dinheiro. Gostaríamos que o consumidor pressionasse a Sabesp, que cobrasse dela atitudes de sustentabilidade, de responsabilidade social e ambiental.

RG: Que mensagem o Akatu gostaria de passar aos nossos leitores, tanto aos possíveis quanto aos atuantes consumidores conscientes?

HM: Nosso slogan diz "consuma sem consumir o mundo em que você vive". Essa é a essência. Acreditamos que as atitudes responsáveis (vindas de empresas, governos etc.) devam ser valorizadas. Ao prestigiar uma empresa com responsabilidade socioambiental, você está ajudando não só o planeta, mas nossa sociedade e as futuras gerações. Aliás, ressalto que esse lema está implícito em nosso nome - Akatu - que vem de duas palavras do tupi antigo: " $A$ ", que quer dizer semente e mundo. Para quem vive na floresta, a semente contém o registro da árvore, que, por sua vez, contém o registro da floresta, que é o mundo, portanto semente e mundo são a mesma coisa. "Katu", que significa bom ou melhor. Ou seja, temos a semente (individual) e o mundo (coletivo). Akatu é a semente boa para um mundo melhor, é um indivíduo bom para um coletivo melhor. Assim, espero que quem leia esta entrevista se torne Akatu, um indivíduo bom para um coletivo melhor.

\section{Notas}

1 Termo introduzido por Adam Smith em A riqueza das nações, para descrever como, numa economia de mercado, apesar da inexistência de uma entidade coordenadora do interesse comum, a interação entre os indivíduos resultaria numa certa ordem, como se existisse uma "mão invisível" que os orientasse.

2 A Uninove apóia o Akatu, no segundo semestre de 2006, por meio do Projeto Boleto On-Line. A idéia é engenhosa: quando qualquer aluno vai efetuar o pagamento da matrícula, ele precisa optar entre duas entidades assistenciais, o Akatu e a Casa Hope, instituição de apoio à criança com câncer. Cada vez que isso ocorre, a Uninove doa 50 centavos à selecionada. Além disso, o Akatu foi convidado a dar palestras e a distribuir materiais impressos e publicações aos mais de 60 mil alunos para difundir a causa do consumo consciente. 
